\title{
Decomposition of Formic Acid Catalyzed by a Phosphine- Free Ruthenium Complex in a Task-Specific Ionic Liquid
}

\author{
Jackson D. Scholten, Martin H. G. Prechtl, and Jairton Dupont ${ }^{*[a]}$
}

The dehydrogenation of formic acid is effectively catalyzed by the $\mathrm{Ru}$ complex $\left[\left\{\mathrm{RuCl}_{2}(p \text {-cymene })\right\}_{2}\right]$ dissolved in the ionic liquid (IL) 1-(2-(diethylamino)ethyl)-3-methylimidazolium chloride at $80^{\circ} \mathrm{C}$ without additional bases. This catalytic system gives TOF values of up to $1540 \mathrm{~h}^{-1}$. Preliminary kinetic insights show formal reaction orders of $0.70( \pm 0.15), 0.78( \pm 0.03)$ and $2.00( \pm 0.17)$ for the Ru catalyst, IL 1 , and formic acid, respectively. The apparent activation energy of this process is esti- mated to be $(69.1 \pm 7.6) \mathrm{kJ} \mathrm{mol}^{-1}$. In addition, dimeric Ru hy dride ionic species involved in the reaction, such as $[\{R u(p-c y m-$ ene $\left.)\}_{2}\left\{(\mathrm{H}) \mu-(\mathrm{H})-\mu-\left(\mathrm{HCO}_{2}\right)\right\}\right]^{+} \quad$ and $\quad\left[\{\mathrm{Ru}(p \text {-cymene })\}_{2}\{(\mathrm{H}) \mu-(\mathrm{Cl}) \mu-\right.$ $\left.\left.\left(\mathrm{HCO}_{2}\right)\right\}\right]^{+}$, are identified by mass spectrometry. The presence of water in large amounts inhibits higher conversions. Finally, a remarkable catalytic activity is observed during recycles, indicating this system's potential for hydrogen gas production.

\section{Introduction}

Currently, there is a strong interest in hydrogen storage to serve an advanced hydrogen-based energy system. ${ }^{[1-4]}$ In this context, one of the most significant challenges of hydrogenbased energy generation is the storage of large quantities of hydrogen at safe pressures. ${ }^{[1]}$ In particular for portable applications, the use of liquid hydrogen has several disadvantages due to its continuous evaporation. Among various storage materials and methods currently under investigation, molecular hydrogen adsorption on materials of large surface area ${ }^{[5-8]}$ and clathrate hydrates, ${ }^{[9]}$ the use of bonded hydrogen atoms in hydrocarbons, ${ }^{[10]}$ metal hydrides ${ }^{[11,12]}$ or formic acid $(F A)^{[13-17]}$ show considerable promise.

The decomposition of FA as a formate-amine adduct, such as the azeotropic mixture comprising $\mathrm{HCO}_{2} \mathrm{H}$ and $\mathrm{NEt}_{3} \quad(5: 2$ molar ratio), is usually the method of choice for hydrogen generation. ${ }^{[18-22]}$ FA decomposition to hydrogen and carbon dioxide can easily be catalyzed by several homogeneous ${ }^{[14,16,18-23]}$ and heterogeneous catalysts. ${ }^{[24]}$ In particular, $\mathrm{Ru}$ phosphine complexes in the presence of a base, such as triethylamine or sodium formate, in water are quite effective catalysts for this transformation. However, these systems use volatile amines and/or water that should be removed before application in fuel cell devices. Very recently, Deng and co-workers indicated that FA decomposition can be catalyzed by $\left[\left\{\operatorname{RuCl}_{2}(p-\right.\right.$ cymene) $\}_{2}$ ] 2 in amine-functionalized ILs in the presence of

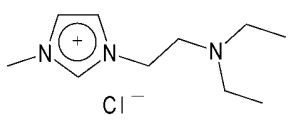

1

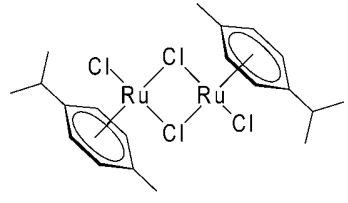

2 sodium formate with turnover numbers of up to 627 in one hour at $60{ }^{\circ} C^{[25]}$ Herein, we report our findings on the decomposition of FA by the phosphine-free $\left[\left\{\mathrm{RuCl}_{2}(p \text {-cymene })\right\}_{2}\right] \mathbf{2}$ in functionalized IL ${ }^{[26,27]} \mathbf{1}$ (Figure 1) in the absence of base, with discussion of kinetic and mechanistic aspects, and identification of the ionic organometallic species involved in this transformation.

\section{Results and Discussion}

The functionalized IL 1 was chosen for study not only because of its basicity and very low vapor pressure, but also because Ru catalyst precursor 2 and the other components (FA and water) are highly soluble in this liquid, whereas the main product is almost insoluble. Therefore, the catalytic system could be considered as one-phase, and the kinetic and mechanistic aspects were investigated using classical homogeneous catalytic models.

Investigation of the catalyst system $\mathbf{1 / 2}$ showed activities with initial turnover frequencies (TOFs) of up to $1540 \mathrm{~h}^{-1}$ without additional solvents or bases. The TOFs were determined from the normalized slopes obtained by online pressure monitoring and calibration by ${ }^{1} \mathrm{H}$ NMR spectroscopy. Preliminary experiments showed that it was crucial to slightly heat $\left(T=40^{\circ} \mathrm{C}\right.$, $\left.80^{\circ} \mathrm{C}\right)$ the reaction mixture of FA $(17.6 \mathrm{mmol}), \mathrm{IL} 1(7.0 \mathrm{mmol})$ and complex 2 ( $6.5 \mu \mathrm{mol}$; Table 1, entries 1 and 2). There was no significant reaction at $25^{\circ} \mathrm{C}$, probably due to a lack of for-

[a] J. D. Scholten, Dr. M. H. G. Prechtl, Prof. Dr. J. Dupont INCT-Catal., Laboratory of Molecular Catalysis, Institute of Chemistry Universidade Federal do Rio Grande do Sul (UFRGS)

Av. Bento Gonçalves 9500, Porto Alegre, RS, Brazil, CEP 90710-501 (Brazil) Fax: (+ 55) 51-3308-7304

E-mail:jairton.dupont@ufrgs.br

Supporting information for this article is available on the WWW under http://dx.doi.org/10.1002/cctc.201000119. 
Table 1. Ruthenium 2-catalyzed FA decomposition using IL 1 as a co-catalyst.

\begin{tabular}{clllllll} 
Entry & $\begin{array}{l}\mathrm{IL} \\
{[\mathrm{mmol}]}\end{array}$ & $\begin{array}{l}\mathrm{FA} \\
{[\mathrm{mmol}]}\end{array}$ & $\begin{array}{l}\mathrm{Ru} \\
{[\mu \mathrm{mol}]}\end{array}$ & $\begin{array}{l}T \\
{\left[{ }^{\circ} \mathrm{C}\right]}\end{array}$ & $\begin{array}{l}t \\
{[\mathrm{~h}]}\end{array}$ & $\begin{array}{l}\text { Conv. } \\
{[\%]^{\left[{ }^{2}\right]}}\end{array}$ & $\begin{array}{l}\text { TOF } \\
{\left[\mathrm{h}^{-1}\right]^{[\mathrm{b}]}}\end{array}$ \\
\hline 1 & 7.0 & 17.6 & 6.5 & 40 & 45 & 31 & $\mathrm{~N} . \mathrm{D}$. \\
2 & 7.0 & 17.6 & 6.5 & 80 & 7 & $91^{[\mathrm{cc}]}$ & 1540 \\
$3^{[\mathrm{d}]}$ & 7.0 & 17.6 & 6.5 & 80 & 24 & 41 & 280 \\
$4^{[\mathrm{e}]}$ & 7.0 & 17.6 & 6.5 & 80 & 22 & 86 & 1684 \\
5 & 2.3 & 17.6 & 6.5 & 80 & 5 & $92^{[\mathrm{f}]}$ & 738 \\
6 & 2.3 & 17.6 & 13.1 & 80 & 3 & 97 & 472 \\
7 & 7.0 & 17.6 & 19.6 & 80 & 6 & $90^{[\mathrm{g}]}$ & 664 \\
8 & 2.3 & 17.6 & 19.6 & 80 & 3 & 99 & 366 \\
9 & 0.9 & 17.6 & 19.6 & 80 & 4 & $91^{[\mathrm{h}]}$ & 206 \\
10 & 2.3 & 26.5 & 19.6 & 80 & 5 & $>99$ & 352 \\
11 & 2.3 & 8.8 & 19.6 & 80 & 2 & $>99$ & 374 \\
12 & 2.3 & 17.6 & 19.6 & 40 & 24 & 87 & 26 \\
13 & 2.3 & 17.6 & 19.6 & 50 & 24 & 91 & 38 \\
14 & 2.3 & 17.6 & 19.6 & 60 & 8 & 99 & 180 \\
15 & 2.3 & 17.6 & 19.6 & 70 & 7 & 98 & 220 \\
16 & 2.3 & 17.6 & 19.6 & 95 & 2 & 99 & 460
\end{tabular}

[a] Formic acid decomposition to $\mathrm{H}_{2}$ and $\mathrm{CO}_{2}(1: 1)$; [b] TOF $=\left(\right.$ mol $\left._{\text {product }}\right)$ / $\left(\mathrm{mol}_{\text {Ru dimer }} \times t\right.$ ) (at $20 \%$ conversion); [c] conversion $>99 \%$ after $17 \mathrm{~h}$; [d] in the presence of water $(1.0 \mathrm{~mL})$; $[\mathrm{e}]$ in the presence of toluene $(1.0 \mathrm{~mL})$; [f] conversion $=99 \%$ after $20 \mathrm{~h}$; [g] conversion $=98 \%$ after $20 \mathrm{~h}$; [h] conversion $>99 \%$ after 20 h. N.D. $=$ not determined.

mation of catalytically active species, which apparently only occurs at higher temperatures. Indeed, at $T=40^{\circ} \mathrm{C}$ (Table 1 , entry 1) conversion was quite low (31\%) at a prolonged reaction time $(45 \mathrm{~h})$. However, at $80^{\circ} \mathrm{C}$, the conversion was over $90 \%$ within $7 \mathrm{~h}$ and was practically complete (>99\%) within $17 \mathrm{~h}$ (Table 1, entry 2). It is worth noting that the obtained catalytic activities (TOFs of up to $1540 \mathrm{~h}^{-1}$ ) reported herein are superior to those recently reported using a $\operatorname{iPr}_{2} \mathrm{NEMimCl} / 2$ at $60^{\circ} \mathrm{C}$ in the presence of sodium formate (TOF up to $\left.627 \mathrm{~h}^{-1}\right) .^{[25]}$ These differences are probably related to the use of strong base, which is known to form $\mathrm{N}$-heterocyclic carbenes by imidazolium deprotonation ${ }^{[28]}$ and/or decompose imidazolium ILs in the presence of water by Hoffman elimination. ${ }^{[29]}$ Water plays an important role in this catalytic reaction; the addition of $1 \mathrm{~mL}$ of water had a detrimental effect (Table 1, entry 3), in contrast to Laurenczy's system, which operates in water. $^{[16]}$ In our system, excess water gave lower conversions, and after $24 \mathrm{~h}$, only $41 \%$ of the FA was dehydrogenated at $80^{\circ} \mathrm{C}$, which corroborates a recent report using the same catalytic system in the presence of an extra base. ${ }^{[25]}$ In this case, the excess of water may make difficult the formation of catalytic active species in the medium, probably as a result of solvation or coordination processes that have a negative effect on the reaction. However, traces of residual water did not drastically influence the catalysis, as all reactions were prepared without the exclusion of humidity. Furthermore, another run was set up with the addition of toluene $(1 \mathrm{~mL})$ to check whether a lower viscosity of the catalyst system (owing to the presence of a cosolvent) supported faster conversion (Table 1 , entry 4). Surprisingly, the conversion was slightly lower $(86 \%$ after $22 \mathrm{~h}$ ).
More importantly, in our investigations we found that high quantities of IL may slow down the catalytic reaction, and that even small amounts are sufficient to make the FA capable of dehydrogenation. Although high amounts of IL make the dehydrogenation faster up to $20 \%$ conversion, the overall reaction is slower when compared to that with low concentrations of the IL (Table 1, entries 2 and 5, 7 and 8), which may be related to the a high viscosity of the medium being attained with a high IL concentration and/or the amine moiety of the IL blocking the active sites of the ruthenium complex. Although no transition species containing the IL-amine as a ligand were detected by electrospray ionization mass spectrometry (ESI-MS) analysis (see later), the second (site-blocking) aspect is in agreement with previous observations, where excess ligands such as phosphine blocked the catalyst active site and drastically lowered the conversion. ${ }^{[16]}$ Moreover, the addition of phosphine ligands to our system completely inhibited the catalytic decomposition of FA. In other words, the active sites of the ruthenium species are blocked by strongly coordinating phosphine ligands. Consequently, we ran a phosphine-free system and tested lower base concentrations in the FA decomposition reaction. Initially, decreasing the IL amount from 7.0 to $2.3 \mathrm{mmol}$ led to a drop in the reaction time under the same conditions (Table 1, entries 7 and 8). However, using $0.9 \mathrm{mmol}$ of the IL did not significantly improve FA decomposition (Table 1, entry 9). Therefore, it was assumed that the best reaction conditions consisted of the use of $2.3 \mathrm{mmol}$ of IL 1 and $19.6 \mu \mathrm{mol}$ of 2 at $80^{\circ} \mathrm{C}$. As expected, increasing the FA concentration (to $26.5 \mathrm{mmol}$ ) increased the reaction time, whereas with a lower quantity $(8.8 \mathrm{mmol})$, the reaction was practically complete in less time and a high conversion was reached after a few hours (Table 1, entries 8,10 , and 11). The stability of the catalyst system was tested by performing recycling experiments using the standard conditions $(2.3 \mathrm{mmol}$ IL 1, $19.6 \mu \mathrm{mol} 2,17.6 \mathrm{mmol} F A, T=80^{\circ} \mathrm{C}$ ). Although a slight decrease in the catalytic activity was observed after the first run, the system proved robust even after five recycles (Figure 2). In all cases, gas-phase analyses of the FA dehydrogenation reactions by mass spectrometry indicated the formation of $\mathrm{H}_{2}$ and $\mathrm{CO}_{2}$ in a 1:1 ratio. Moreover, carbon monoxide was detected in

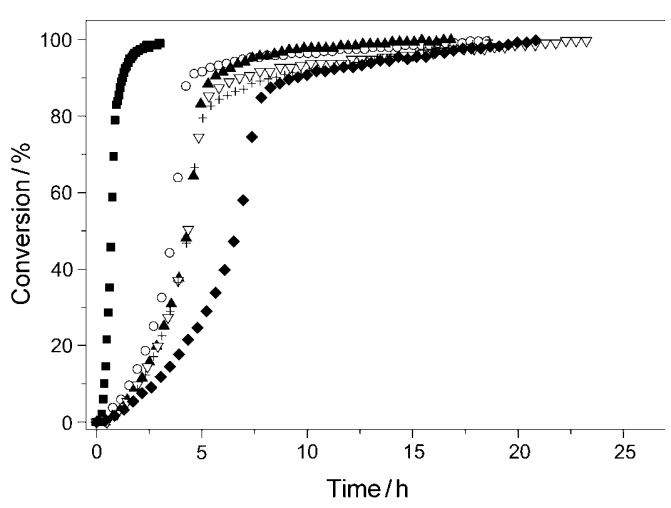

Figure 2. Reaction profiles for FA $(0.81 \mathrm{~g} ; 17.6 \mathrm{mmol})$ decomposition catalyzed by Ru complex $2(0.012 \mathrm{~g} ; 19.6 \mu \mathrm{mol})$ in IL $1(0.5 \mathrm{~g} ; 2.3 \mathrm{mmol})$ at $80^{\circ} \mathrm{C}$ for 6 cycles: $1^{\text {st }} ; \bigcirc 2^{\text {nd }}, \Delta 3^{\text {rd }}, \nabla 4^{\text {th }} ; \bullet 5^{\text {th }} ;+6^{\text {th }}$ cycle. 
trace amounts in the gas-phase of the reactions by infrared analysis (Figure 3).

It is important to note that no CO was detected by gas chromatography $(\mathrm{GC})$ analysis indicating that the $\mathrm{CO}$ concentration

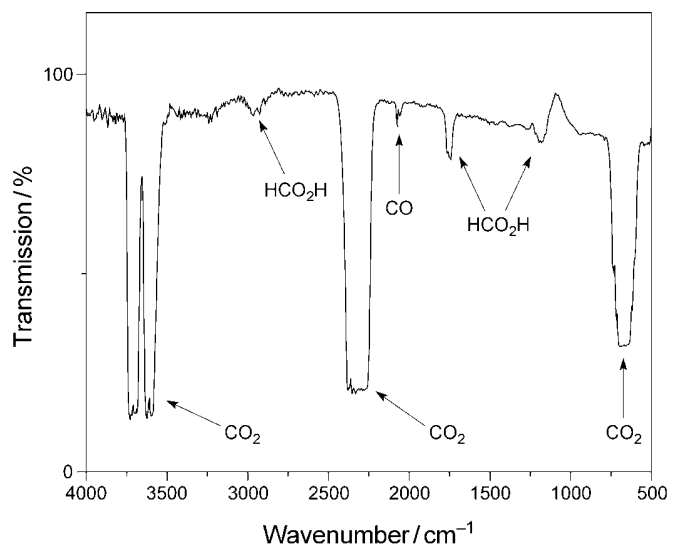

Figure 3. Infrared spectrum of the gas-phase after FA decomposition catalyzed by Ru complex $\mathbf{2}$ in IL $\mathbf{1}$ at $80^{\circ} \mathrm{C}$. Conditions as for Figure 2 .

is below the detection limit of the detector (TCD, $10 \mathrm{ppm}$ ). This result is similar to those reported previously by Beller and co-workers. ${ }^{[21]}$ However, a week CO stretching was detected by IR spectroscopy indicating its concentration was in the range 1-10 ppm in the gas-phase. Since CO generation implies water formation (dehydration of FA), the water content was also monitored by mass spectrometry (MS). In fact, no water was detected in the gas-phase by MS, again indicating a CO production less than $10 \mathrm{ppm}^{[30]}$ (see the Supporting Information). Although the time for complete conversion on the recharges was slightly higher than the first run, the presence of traces of $\mathrm{CO}$ did not significantly influence the catalytic activity of the system. The reaction parameters of this homogeneous system at different temperatures $\left(40-95^{\circ} \mathrm{C}\right)$, catalyst loadings $(6.5-$ $19.6 \mu \mathrm{mol})$, substrate loadings $(8.8-26.5 \mathrm{mmol})$ and base amounts (0.9-7.0 mmol) are summarized in Table 1.

Using the determined initial rate constants of the selected curves at low conversions ( $<20 \%)$, it was possible to estimate the formal reaction order for this catalytic system (see the Supporting Information). From a double logarithmic plot of the initial rates, a formal "broken" reaction order $(0.70 \pm 0.15)$ was deduced for catalyst 2 (constant IL and FA amounts of 2.3 and $17.6 \mathrm{mmol}$, respectively; Table 1, entries 5, 6 and 8). The reaction order with respect to IL 1 was also checked by variation of its concentration at a constant catalyst loading of $19.6 \mu \mathrm{mol}$ of 2 and $17.6 \mathrm{mmol}$ of $\mathrm{FA}$ at $80^{\circ} \mathrm{C}$ (Table 1, entries 7-9), and showed a similar order $(0.78 \pm 0.03)$. Broken reaction orders are usually related to the formation of the active species. In this case, it is probable that not all of the Ru precursor gives Ru hydrides, but also gives other Ru species (neutral complexes, for example) that could not be identified by ESI analysis (see further). This entire process was possibly supported by the IL 1 . Furthermore, a formal reaction order for the FA substrate was determined in a similar manner, which showed a second-order dependence $(2.00 \pm 0.17$; Table 1 , entries 8,10 and 11$)$. Thus, this preliminary result suggests that FA is present in its dimeric form during the catalytic reaction. The influence of the reaction temperature was investigated with the standard system $(19.6 \mu \mathrm{mol} 2,2.3 \mathrm{mmol}$ IL $1,17.6 \mathrm{mmol} F A)$ in the range of 40 $95^{\circ} \mathrm{C}$ (Table 1, entries 8 and 12-16; Figure 4). The slope of the

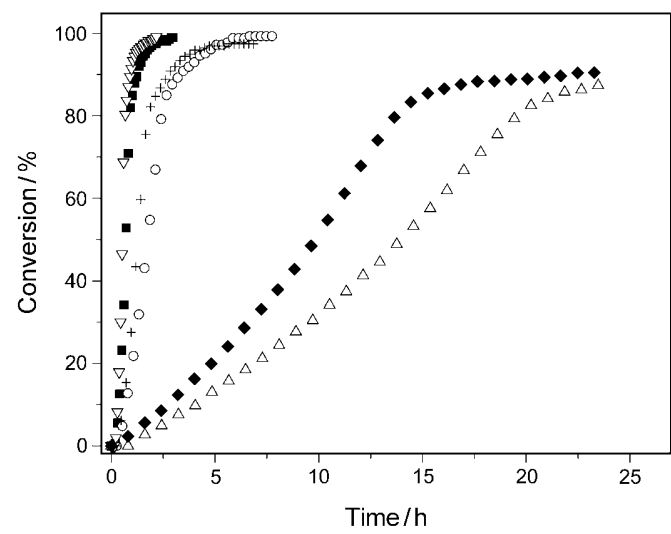

Figure 4. FA decomposition catalyzed by Ru complex 2 in IL 1 at different temperatures: $\nabla 95^{\circ} \mathrm{C} ; 80^{\circ} \mathrm{C} ;+70^{\circ} \mathrm{C} ; 060^{\circ} \mathrm{C} ; 50^{\circ} \mathrm{C} ; \Delta 40^{\circ} \mathrm{C}$. Amounts as for Figure 2 .

line up to $20 \%$ conversion (initial rate) was used to determine the apparent activation energy of the process. From the Arrhenius plot (Figure 5), the activation energy was derived as $E_{\mathrm{a}}=$ $69.1 \pm 7.6 \mathrm{~kJ} \mathrm{~mol}^{-1}$. This activation energy fits in the range of the most active catalyst systems previously reported for the dehydrogenation of FA. ${ }^{[24]}$ In general, heterogeneous catalysts have activation energies higher than $100 \mathrm{~kJ} \mathrm{~mol}^{-1}$. 31$]^{2}$

Moreover, the standard catalytic system was investigated by means of ESI-MS techniques for the detection of ruthenium complexes during the catalysis. For the detection of intermediates and organometallic complexes in dilute homogeneous solutions, especially in IL systems, ESI-MS spectrometry is the most powerful and convenient tool, and is best known as ion fishing. ${ }^{[32-38]}$ An aliquot of the reaction mixture was taken after $45 \mathrm{~min}$ (ca. $50 \%$ conversion), and the sample was analyzed in

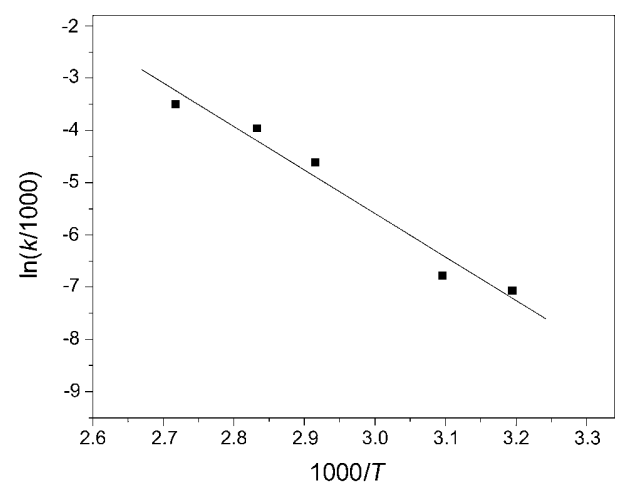

Figure 5. Arrhenius plot for the determination of the apparent activation energy of the process $\left(E_{\mathrm{a}}=69.1 \pm 7.6 \mathrm{~kJ} \mathrm{~mol}^{-1}\right)$. Reaction conditions: Amounts as for Figure $2 ; T=40-95^{\circ} \mathrm{C}$. 
water. The ESI(+)-MS spectrogram (Figure 6) showed the IL $(\mathrm{m} /$ $z=182.07)$ and two ruthenium species with signal sets at around 518.81 and 552.76 . Both signal sets had the typical iso-

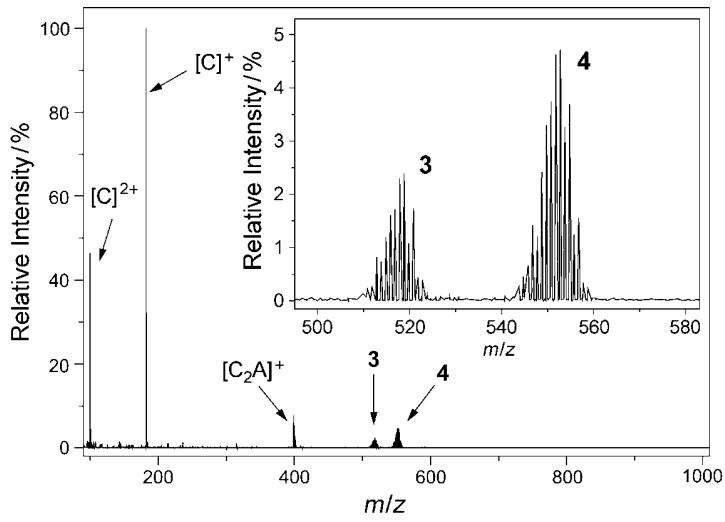

Figure 6. $\mathrm{ESI}(+)-\mathrm{MS}$ analysis of FA dehydrogenation catalyzed by Ru complex $\mathbf{2}$ in IL 1, analyzed at $50 \%$ of conversion. Conditions as for Figure 2 . The inset shows the signals of intermediary ruthenium species $3(\mathrm{~m} / \mathrm{z}=518.81)$ and $4(m / z=552.76)$. [C] $]^{+}$corresponds to the cation of IL $1,[C]^{2+}$ is the protonated dicationic IL 1 and $\left[C_{2} A\right]^{+}$is one cluster where $A$ is the anion.

topic distribution for ruthenium. Considering the dimeric ruthenium precursor $\mathbf{2}$ with a chloride bridge, we observed some evidence of dimeric ruthenium complexes $\mathbf{3}$ and $\mathbf{4}$, with a formate-hydride bridge and formate-chloride bridge, respectively (Figure 7). Formate-bridged ruthenium dimers have been previously reported for the ruthenium-catalyzed dehydrogenation of $\mathrm{FA}^{[22]}$ where a simple ligand exchange between halide and formate is likely to occur and can be easily understood in presence of excess FA. The analysis of both main signals $(\mathrm{m} /$ $z=518.81$ and 552.76) with higher energies (50 V) in the $\mathrm{ESI}(+)-\mathrm{MS} / \mathrm{MS}$ experiments showed the loss of the formate bridge ligand, with the ruthenium fragments rearranged. In the case of Ru complex 3, a formerly terminal hydride acts as a hydride bridge in proposed ruthenium dimer $5(\mathrm{~m} / \mathrm{z}=473.84)$, and chloride-bridged ruthenium dimer $6(m / z=507.78)$ is formed after the fragmentation of Ru complex 4 (Figure 7). The ESI(+)-MS/MS experiments also showed that the formate ligand in the stable dimers $\mathbf{3}$ and $\mathbf{4}$ can be eliminated more easily and with reasonably low energies in the gas-phase, rather than a hydride or chloride being eliminated under these conditions. Additionally, for the proposed complexes (3 and 4), the theoretical isotope modeling fit well with the experimental data, which strengthens the assumed presence of the catalytic species in a dimeric form. Consequently, the calculated TOFs are based on ruthenium dimers and not ruthenium monomers.

Attempts to characterize the related ruthenium species in situ by ${ }^{1} \mathrm{H}$ and ${ }^{13} \mathrm{C}$ NMR spectroscopy failed, probably due to the very low $\mathrm{Ru}$ concentration becoming difficult to obtain NMR spectra from the crude reaction mixture.

To prove the high potential of our in situ-formed catalytic system $\mathbf{1 / 2}$, we considered the use of the corresponding solid hydrochloride of the amine-functionalized IL (soluble in FA),
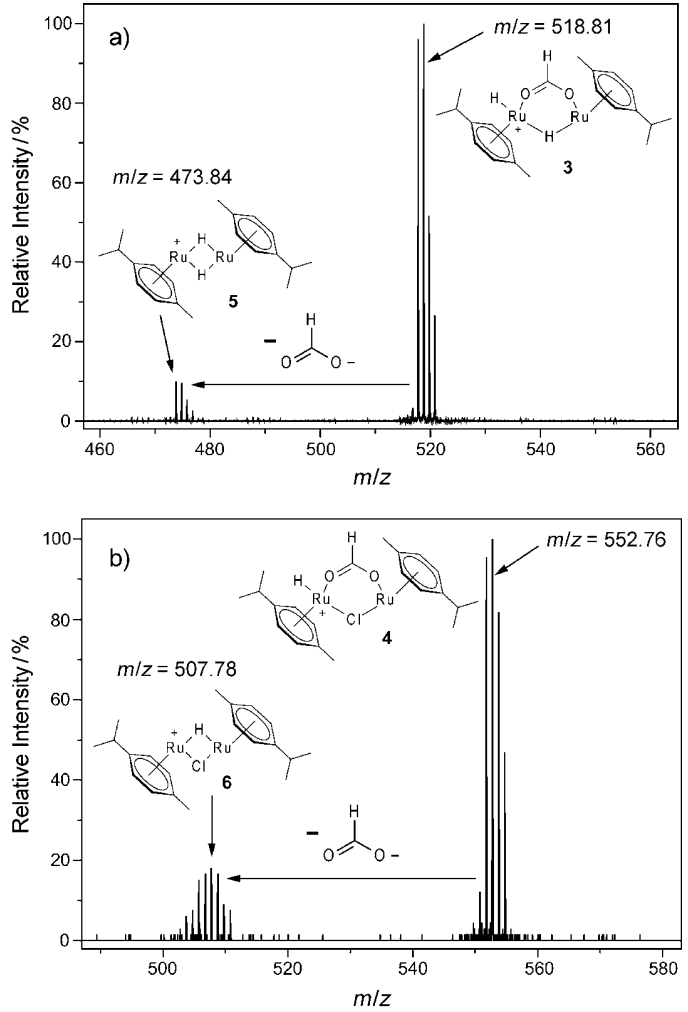

Figure 7. $\mathrm{ESI}(+)-\mathrm{MS} / \mathrm{MS}$ analysis of the signals in Figure $6:$ a) $m / z=518.81$ (3); b) $m / z=552.76$ (4). Capillary voltage $=3050$ V; Sample cone voltage $=50 \mathrm{~V}$.

IL $\mathbf{1} \cdot \mathrm{HCl}$, which renders the last synthetic step with IL $\mathbf{1}$ (deprotonation) unnecessary. Indeed, the formation of a catalytically active ruthenium species and the deprotonation (in equilibrium) of FA with the IL $\mathbf{1} \cdot \mathrm{HCl}$ was possible under identical reaction conditions, and resulted in a moderate conversion of $60 \%$ after $25 \mathrm{~h}$ ( $50 \%$ after $9 \mathrm{~h}$; see the Supporting Information). Such a long reaction time compared to that performed in IL 1 is a probable consequence of IL $\mathbf{1} \cdot \mathrm{HCl}$ crystallization during the course of the reaction. Notably, the conversions were estimated here by fitting the pressure curves using the previously calibrated and normalized conversion curves. This was crucial because at high conversions of $\mathrm{FA}$, the IL $1 \cdot \mathrm{HCl}$ started to crystallize from the FA/formate solution; thus, IL 1.HCl backbone signals could not be used as an internal standard for quantification by ${ }^{1} \mathrm{H} N M R$ spectroscopy. Interestingly, a very low concentration of IL $1 \cdot \mathrm{HCl}(39.2 \mu \mathrm{mol} ; 1$ equivalent with respect to $\mathrm{Ru}$ ) still produced a conversion of $30 \%$ after $20 \mathrm{~h}$ (see the Supporting Information).

\section{Conclusions}

In conclusion, we have demonstrated the easy conversion of FA into dihydrogen and carbon dioxide gas using phosphinefree ruthenium complex $\left[\left\{\mathrm{RuCl}_{2}(p \text {-cymene })\right\}_{2}\right] 2$ in a task-specific IL. The task-specific IL 1 stabilizes the active catalyst species and the immobilized amine group acts as crucial promoter for the dehydrogenation of FA. High conversions (TOF values of up to $1540 \mathrm{~h}^{-1}$ ) of FA dehydrogenation could be obtained in a 
few hours under mild conditions. Kinetic measurements indicated formal broken reaction orders of $0.70 \pm 0.15$ and $0.78 \pm$ 0.03 for catalyst $\mathbf{2}$ and IL 1, respectively, whereas the reaction order was estimated as $2.00 \pm 0.17$ for FA, suggesting that FA is present in its dimeric form during the catalytic reaction. The apparent activation energy of this process was estimated to be $69.1 \pm 7.6 \mathrm{~kJ} \mathrm{~mol}^{-1}$, which is in the range of the most common catalytic systems used for FA dehydrogenation. Moreover, ESI(+)-MS analyses showed ionic dimeric Ru complexes (3 and 4) as probable catalytic species involved in the FA decomposition. The stability to air and humidity and potential for catalyst recycling suggests that the catalyst system is quite robust and easy to handle, indicating it as a potential system for hydrogen gas production. Interestingly, the reaction was also possible with $\mathrm{IL} \mathbf{1} \cdot \mathrm{HCl}$ as a promoting agent.

\section{Experimental Section}

\section{General}

All manipulations were performed in air. Ruthenium complex 2 (di$\mu$-chlorobis[( $p$-cymene)chlororuthenium(II)]) was purchased from STREM and used as received. The FA ( $88 \%$, Labsynth) was distilled and used without further purification. ${ }^{1} \mathrm{H}$ NMR spectra were recorded on a Varian Inova $300 \mathrm{MHz}$ instrument using $\left[\mathrm{D}_{6}\right] \mathrm{DMSO}$ as the solvent. Mass spectra were obtained using a QIC-20 Hiden Analytical gas analyzer. An aliquot of the gas-phase was introduced to a pre-reservoir and then this sample was injected into the mass analyzer. Electrospray ionization mass spectrometry (ESI(+)-MS) analyses were performed on a Waters micromass Q-Tof microTM instrument operating at $2750 \mathrm{~V}$ of capillary voltage and $13 \mathrm{~V}$ of sample cone voltage. For ESI analysis, $5 \mathrm{mg}$ of the reaction mixture was first diluted in $1 \mathrm{~mL}$ of water. Thereafter, one drop of this solution was diluted again in $1 \mathrm{~mL}$ water and then the sample was analyzed. Infrared analyses of the gas-phase were obtained using a Bomem FTLA 2000 equipped with a DRIFT cell (Harrick Praying Mantis reaction chamber). At the end of the reaction, the DRIFT cell was pressurized with the gas contained in the reactor (ca. $2 \mathrm{MPa}$ ) and the gas phase was analyzed at $25^{\circ} \mathrm{C}$. Gas chromatography analyses were carried out in Agilent Technologies equipment using a TCD detector. Analysis condition: column = SupelcoMolecular Sieves $5 \mathrm{~A}$; column temperature $=100^{\circ} \mathrm{C}$; detector temperature $=150^{\circ} \mathrm{C}$; time for analysis $=20 \mathrm{~min}$; carrier gas $=\mathrm{He}$.

\section{Synthesis of IL 1}

IL 1 was prepared using a similar method to that previously reported. ${ }^{[39]}$ First, IL $1 . \mathrm{HCl}$ was prepared from the reaction of 1-methylimidazole (19.1 g; $232.4 \mathrm{mmol}$ ) and 2-chloro- $\mathrm{N}, \mathrm{N}$-diethylethylamine hydrochloride $(40.0 \mathrm{~g} ; 232.4 \mathrm{mmol})$ in acetonitrile $(200 \mathrm{~mL})$ under reflux conditions. After 4-5 days of reaction, a white solid was separated by filtration and washed with a $1: 1 \mathrm{v} / \mathrm{v}$ mixture of ethyl ether and acetonitrile $(3 \times 80 \mathrm{~mL})$. The resultant white solid was dried under reduced pressure to afford IL $1 \cdot \mathrm{HCl}$ in $90 \%$ yield. Further, deprotonation of IL $1 \cdot \mathrm{HCl}(15.0 \mathrm{~g} ; 58.9 \mathrm{mmol})$ with $\mathrm{NaOH}$ $(2.4 \mathrm{~g} ; 58.9 \mathrm{mmol})$ in water $(150 \mathrm{~mL})$ was carried out for $2 \mathrm{~h}$. Water was then removed under reduced pressure and the liquid residue was extracted with dichloromethane $(100 \mathrm{~mL})$. The organic phase was dried over $\mathrm{MgSO}_{4}$ and filtered through celite/neutral alumina. The solvent was removed under reduced pressure to afford the de- sired IL 1 in good yields (76-98\%). Finally, IL 1 was dried under vacuum for $5 \mathrm{~h}$ at $50^{\circ} \mathrm{C}$.

\section{Formic acid dehydrogenation}

In a typical FA decomposition experiment, IL 1 ( $0.5 \mathrm{~g} ; 2.3 \mathrm{mmol})$ was mixed with FA $(0.81 \mathrm{~g} ; 17.6 \mathrm{mmol})$ in a glass reaction vessel. Afterwards, the mixture was stirred until it became a homogeneous solution, and then Ru complex $2(0.012 \mathrm{~g} ; 19.6 \mu \mathrm{mol})$ was added. The vessel containing the solution was placed into a highpressure Parr reactor. The system was then immersed in a silicon oil bath at $80^{\circ} \mathrm{C}$ under stirring. A sample was analyzed by ${ }^{1} \mathrm{H}$ NMR before and after reaction, where signals of IL 1 were used as the internal standard to determine the conversion based on FA/IL 1 integral ratios. For recharges, at the end of each cycle, more FA $(0.81 \mathrm{~g} ; 17.6 \mathrm{mmol})$ was added to the system and the reaction was restarted. The increase in the gas pressure in the reactor was monitored with a pressure transducer interfaced through a Novus converter to a PC, and the data was worked up via Microcal Origin 7.0.

\section{Acknowledgements}

The authors would like to thank the CNPq, CAPES, Petrobras and the Alexander-von-Humboldt Foundation (MHG Prechtl) for funding.

Keywords: dehydrogenation - formic acid - homogeneous catalysis · ionic liquid $\cdot$ ruthenium

[1] L. Schlapbach, A. Zuttel, Nature 2001, 414, 353-358.

[2] S. Enthaler, ChemSusChem 2008, 1, 801-804.

[3] F. Joó, ChemSusChem 2008, 1, 805-808.

[4] P. Makowski, A. Thomas, P. Kuhn, F. Goettmann, Energy Environ. Sci. 2009, 2, 480-490

[5] P. Chen, X. Wu, J. Lin, K. L. Tan, Science 1999, 285, 91-93.

[6] C. Liu, Y. Y. Fan, M. Liu, H. T. Cong, H. M. Cheng, M. S. Dresselhaus, Science 1999, 286, 1127-1129.

[7] G. Mpourmpakis, G. E. Froudakis, G. P. Lithoxoos, J. Samios, Nano Lett. 2006, 6, $1581-1583$.

[8] S. Meng, E. Kaxiras, Z. Y. Zhang, Nano Lett. 2007, 7, 663-667.

[9] H. Lee, J. W. Lee, D. Y. Kim, J. Park, Y. T. Seo, H. Zeng, I. L. Moudrakovski, C. I. Ratcliffe, J. A. Ripmeester, Nature 2005, 434, 743-746.

[10] Y. G. Wang, N. Shah, G. P. Huffman, Energy Fuels 2004, 18, 1429-1433.

[11] J. Yang, A. Sudik, D. J. Siegel, D. Halliday, A. Drews, R. O. Carter, C. Wolverton, G. J. Lewis, J. W. A. Sachtler, J. J. Low, S. A. Faheem, D. A. Lesch, V. Ozolins, Angew. Chem. 2008, 120, 896-901; Angew. Chem. Int. Ed. 2008, 47, 882-887.

[12] V. Ozolins, E. H. Majzoub, C. Wolverton, J. Am. Chem. Soc. 2009, 131, $230-237$.

[13] P. Mars, J. J. F. Scholten, P. Zwietering, Adv. Catal. 1963, 14, 35-113.

[14] C. Fellay, P. J. Dyson, G. Laurenczy, Angew. Chem. 2008, 120, 4030-4032; Angew. Chem. Int. Ed. 2008, 47, 3966-3968.

[15] S. Fukuzumi, T. Kobayashi, T. Suenobu, ChemSusChem 2008, 1, 827834.

[16] C. Fellay, N. Yan, P. J. Dyson, G. Laurenczy, Chem. Eur. J. 2009, 15, 3752 3760 .

[17] G. N. Khairallah, R. A. J. O'Hair, Int. J. Mass Spectrom. 2006, 254, 145 151.

[18] B. Loges, A. Boddien, H. Junge, M. Beller, Angew. Chem. 2008, 120 4026-4029; Angew. Chem. Int. Ed. 2008, 47, 3962-3965.

[19] A. Boddien, B. Loges, H. Junge, M. Beller, ChemSusChem 2008, 1, 751 758.

[20] B. Loges, A. Boddien, H. Junge, J. R. Noyes, W. Baumann, M. Beller, Chem. Commun. 2009, 4185-4187. 
[21] H. Junge, A. Boddien, F. Capitta, B. Loges, J. R. Noyes, S. Gladiali, M. Beller, Tetrahedron Lett. 2009, 50, 1603-1606.

[22] D. J. Morris, G. J. Clarkson, M. Wills, Organometallics 2009, 28, 4133 4140.

[23] S. Fukuzumi, T. Kobayashi, T. Suenobu, J. Am. Chem. Soc. 2010, 132, $1496-1497$.

[24] M. Ojeda, E. Iglesia, Angew. Chem. 2009, 121, 4894-4897; Angew. Chem. Int. Ed. 2009, 48, 4800-4803.

[25] X. Li, X. Ma, F. Shi, Y. Deng, ChemSusChem 2010, 3, 71-74.

[26] Z. F. Fei, T. J. Geldbach, D. B. Zhao, P. J. Dyson, Chem. Eur. J. 2006, 12, $2123-2130$.

[27] J. H. Davis, Chem. Lett. 2004, 33, 1072-1077.

[28] J. D. Scholten, J. Dupont, Organometallics 2008, 27, 4439-4442.

[29] J. E. L. Dullius, P. A. Z. Suarez, S. Einloft, R. F. de Souza, J. Dupont, J. Fischer, A. De Cian, Organometallics 1998, 17, 815-819.

[30] The relative component content of a sample is classified as follows: Major $=1-100 \%$; minor $=0.01-1 \%$; trace $<0.01 \%$; ultra-trace $\leq 1 \mathrm{ppb}$. J. F. Rubinson, K. A. Rubinson, Contemporary Chemical Analysis, Prentice Hall, Upper Saddle River, NJ, 1998, Chap. 5, pp. 141-143.

[31] R. Larsson, M. H. Jamroz, M. A. Borowiak, J. Mol. Catal. A: Chem. 1998, $129,41-51$.
[32] L. S. Santos, C. H. Pavam, W. P. Almeida, F. Coelho, M. N. Eberlin, Angew. Chem. 2004, 116, 4430-4433; Angew. Chem. Int. Ed. 2004, 43, 43304333.

[33] F. C. Gozzo, L. S. Santos, R. Augusti, C. S. Consorti, J. Dupont, M. N. Eberlin, Chem. Eur. J. 2004, 10, 6187-6193.

[34] A. A. M. Lapis, B. A. D. Neto, J. D. Scholten, F. M. Nachtigall, M. N. Eberlin, J. Dupont, Tetrahedron Lett. 2006, 47, 6775-6779.

[35] M. H. G. Prechtl, J. D. Scholten, J. Dupont, J. Mol. Catal. A: Chem. 2009, 313, 74-78.

[36] M. N. Eberlin, Eur. J. Mass Spectrom. 2007, 13, 19-28.

[37] C. Daguenet, R. Scopelliti, P. J. Dyson, Organometallics 2004, 23, 4849 4857.

[38] C. Daguenet, P. J. Dyson, Organometallics 2004, 23, 6080-6083.

[39] M. V. Jiménez, J. J. Perez-Torrente, M. I. Bartolome, V. Gierz, F. J. Lahoz, L. A. Oro, Organometallics 2008, 27, 224-234.

Received: April 14, 2010

Revised: May 12, 2010

Published online on August 2, 2010 